\title{
A Dynamic and Psychosocial Analysis of Soccer: Problems and Solutions
}

\author{
Sonny Joseph \\ Psychiatry, Dr. Phillips Hospital Physician's Office, Orlando, Florida, USA
}

\section{Email address:}

ajapjosephmd@aol.com

To cite this article:

Sonny Joseph. A Dynamic and Psychosocial Analysis of Soccer: Problems and Solutions. American Journal of Applied Psychology. Vol. 4, No. 3, 2015, pp. 66-75. doi: 10.11648/j.ajap.20150403.14

\begin{abstract}
Integrating aspects of playing dynamics, psychosocial insights derived from expertise in clinical psychology, psychiatry and public health, soccer observations, years of playing and refereeing experience, and literature review, the article offers a new perspective of soccer based on a qualitative analysis of the various problems such as critical and game-changing refereeing errors due to lack of sufficient objectivity, excessive fouling, scarcity of goals, the near impossibility of a solo run, flagrant fouling and disabling of gifted players, and the disproportionately frequent fan frustration and violence. The article argues that it is of unique importance in soccer that critical calls by the referee should be nearly $100 \%$ accurate primarily because the outcomes of most games are decided by a total of one or two goals. Theories are suggested as to why FIFA (Federation Internationale de Football Association) does not allow the referee to verify critical calls using IVR (Instant Video Review or Replay). Creative solutions are proposed for stimulating lively debate.
\end{abstract}

Keywords: Soccer, FIFA, Football, Fouls, Fan Behavior, Pele, Messi, Ronaldo, Neymar

\section{Admitting the Extent of the Problem-the Most Difficult Step}

The often-expressed aphorism, "this is soccer", is a pleasant rationalization whenever IVRs show major gamechanging mistakes by the referee involving bad calls or no calls. We often use a similar phrase, "that's life" (as if nothing can be done about it, so get used to it) to rationalize the injustices, accidents and crimes that regularly occur in our society. Although a fatalistic attitude is reflected in both contexts, soccer is a man-made game with man-made rules for the enjoyment of the fans and the players and, as such, its rules and their implementation can be fairly easily modified and enforced by FIFA. Soccer, being an interactive, fastpaced, intense, and light-contact sport, involves occasional accidental injuries that are inherent and inevitable. However, many of the injuries and problems associated with the sport are not necessarily inevitable. In order to improve the playing dynamics, and minimize player and fan frustration, I intend to analyze its shortcomings and discuss the following difficult questions with an eye for suggesting reasonable solutions without diminishing the game's intensity and competitiveness: Why do players often resort to both ordinary and flagrant fouls, undermining the fairness, beauty, and elegance of soccer? Why do players often have to employ histrionics to help their teams? Why is soccer the only major sport that does not use IVR to enforce rules in this day and age? What more could FIFA do to protect its elite players who are its most valuable assets? Most importantly, what causes the disproportionately more frequent fan frustration and violence in soccer compared to other sports, and what solutions could be offered to make it more entertaining? The author believes that the scarcity of goals in open play is actually a symptom of the need for some creative solutions to enhance the vibrancy and inherent beauty of soccer.

Although the intent of the article is to suggest constructive and creative solutions in order to benefit the game, players, coaches, FIFA and the millions of fans, it is necessary to first identify, describe and analyze the problems in some detail without minimizing or overstating the extent of the problem in order to provide the readers the proper perspective and rationale for the suggested solutions. The author is also sensitive to the psychological fact that, for both individuals and organizations, it is easier to deny their problems than it is to admit them and deal with them. This article presents a unique perspective on soccer, integrating playing dynamics, years of soccer observation, references to publications and digital media in the public domain (see reference list), 
clinical thinking, application of psychosocial principles, insights gained from many years of playing and refereeing soccer games, and devotion to soccer as a die-hard fan, all founded on the author's expertise in clinical psychology, psychiatry, and public health. Although the article primarily refers to competitive and professional soccer, included are a few instructive examples from the FIFA 2014 World Cup (WC), which, in the author's opinion, with some exceptions, presents somewhat polished games because the players are the cream of the crop, and are usually on their best behavior. Furthermore, they tend not to take as many risks when they play for their national teams as they do when they play for their club teams, and know they are being watched by the whole world. Despite some innovative concepts and solutions presented for stimulating debate that may be hard for some to initially consider, the overall spirit of the treatise is intended to engender optimism and motivation for constructive action. In keeping with the standard expectation of a reputable academic journal, nothing in this article should be considered dogmatic.

Soccer is inherently a beautiful spectator sport because it is fluent, fast, graceful, simple, highly interactive and skillful. Even near misses in soccer can be everlastingly beautiful, such as the goals Pele barely missed against Uruguay ${ }^{1}$ and Czechoslovakia $^{2}$ in the 1970 WC. Soccer offers tremendous opportunity for coordinated team play as well as for individual playmaking and solo runs when intentional fouls are held in check by sufficiently strict and accurate enforcement so as to be a deterrent to the fouling player and team. When fair play is positively reinforced and fouling is discouraged by reliable and meaningful enforcement, players are likely to focus their enormous physical capabilities, and tactical and technical skills on constructive plays, instead of fouls. The way soccer is played now is often fraught with many ordinary fouls that kill the momentum and most solo runs, and punished with just a free kick comparable to a slap on the wrist, and bad calls or no calls. Added to these issues are player injuries, fan frustration and hooliganism. The game is also interrupted due to player conflicts and tantrums and players feigning and exaggerating injuries. Even some friendly games are played with contention and low open goal averages. For example, a recent friendly game between Brazil and Colombia ${ }^{16}$ still resulted in about 50 stoppages including 30 for ordinary fouls, 4 for yellow cards and one for a straight red card. Upon issuing the red card, the referee was mobbed and intimidated by the players, and had to keep backing off as if cautiously evading a pack of predators to avoid being attacked, wasting nearly 2 minutes of precious playing time. Neymar, who was playing his first game after the vertebral fracture, was fouled hard by the same player (earning a yellow card) who committed the flagrant foul causing the vertebral fracture in WC $2014^{8}$, with no consideration at all that this was just a friendly game of no consequence and that he was still fresh from that nearly career-ending injury.

In some instances, even the one or two goals that are scored come from corner or free kicks, generating a hustle involving pushing, shoving, blocking, elbowing and pulling in the penalty box, behavior I am tempted to describe as a melee rather than tactical play. If both teams can "win" enough such hustles in or near the penalty box, causing a near brawl and get lucky, it could produce a goal, either through a chance deflection or a self-goal. Although statistically the majority of goals are scored from open play, the statistic practically has no meaningful validity when only one to two goals are scored in many games. ${ }^{3,4}$ In fact, if goals from set plays and penalties are excluded from the statistic, the average goal per game from open play drops to slightly more than one per game ${ }^{.3,4}$ The fact that not enough goals are scored in open play, forcing the teams to resort to manipulate for free kicks and corner kicks and hoping that the ensuing scramble will produce a goal and a win, reflects the need for improving the open play dynamics of the game. Rather than get bogged down on the various statistics which vary slightly from league to league, let us focus on the big picture.

Due to the scarcity of goals, there is very little outcome differentiation between a weak and a strong team, which leaves considerable room for chance factors, made worse by the referee's inherently human limitation in accurately calling the actions of the players. Metrics related to games have shown that about $45 \%$ of the goals are attributed to luck, and goal-scoring and winning is a $50-50$ proposition ${ }^{5}$ Despite the apparent ball movement in soccer, the game is stuttered by fouls and free kicks that make portions of the game fretful, and have no effect in making it entertaining for players, spectators, and the TV audience. A common saying among soccer players and managers is, "any given day, any team can beat any other team," making the game almost sound like a gamble, where if you play frequently enough, chance alone will get you a win. (The most recent version of this during the WC 2014 was something like, "the soccer gods make up their own mind," meaning one cannot predict the outcome in soccer regardless of how good or bad the team is.) Never mind the exceptional teams like Brazil or exceptional players like Pele, Maradona, Messi, Neymar, and Ronaldo. The fact that they dominated simply underscores their greatness in spite of the endless fouling. Remember, Pele could not play fully in the 1966 World Cup and in many games in the 1960's due to repeated flagrant and sometimes vicious fouling injuries ${ }^{11}$ Out of disgust, frustration and fear of sustaining permanent injury, Pele vowed to never play in another World Cup ${ }^{3,7,12}$ Imagine, arguably the greatest soccer player of all time could not fully participate in the biggest soccer event due to totally preventable, deliberate and unlawful actions of opponents, and millions of fans were deprived of the opportunity of enjoying his brilliance! Because the tickets for such games typically are sold months in advance, the fans have no recourse of canceling and receiving a refund if a superstar player is suddenly unable to play. If given a choice, why should anyone pay a premium to see Argentina play without Messi or Brazil play without Neymar, especially when tickets are sold with the implicit understanding that they will be in the lineup? To be fair, it should be noted that enforcement of fouling has generally improved compared to 
Pele's era, but still leaves much to be desired as was so graphically illustrated by the vicious foul on Neymar ${ }^{8}$ during WC 2014. The serious and crippling injury he suffered, Brazil's loss of their best player and their subsequent disastrous performance, the disappointment of millions of fans all over the world losing the chance to enjoy the play of a superstar in action and the lack of appropriate punishment, act to remind everyone that flagrant fouling of a superstar with game-changing consequences, and the perpetrator virtually getting away with it are still alive and well (déjà vu Brazil1966). A study of the history of soccer will convince one that incidents of stars getting injured, disabled, and sidelined and unable to play in entire tournaments are not that uncommon (Maradona 1980's, Pele 1960's, Best 1960's, van Basten 1992, Ramos 1994, and countless others, with Neymar being the latest) $)^{3,4,15}$. The stark reality that they still occur cannot be ignored as the Neymar case has shown. It is especially important to explain to the many millions of his adoring teenage fans all over the world what happened to their idol and assure them that the leadership will take reasonable and responsible action to protect the stars from such reckless injuries in the future. Otherwise it is easy for the youth of our generation that are exposed to soccer to grow up being cynical about soccer, an attitude which might even generalize to the larger society. Now, the leadership could technically be correct and take a strict logical stance that soccer is just a game and a business, and therefore is not concerned about its social consequences. However, by implementing rules that assure fundamental fairness and protection for the players in order to minimize incapacitating injuries, not only the game but also the society will benefit, and the idolizing teenagers, instead of becoming cynical, will grow up with more respect for law and order as it relates to soccer and society. As Pele explained in his recent book, soccer matters a lot as the most popular sport in the world ${ }^{13}$. It is certainly not FIFA's fault that players get injured, because many variables are involved in such injuries. However, I believe FIFA is in a leadership position to do more to protect the players, referee and fans from conflicts, abuse and injuries. Obviously, accidental injuries happen in any contact sport. Although it is very true that what is rare has more value, one does not want to make the goals in soccer so scarce and so prized that players have to resort to gamesmanship and take extraordinary risk to self or other players to score or defend a goal. Such an atmosphere surrounding a game causes unnecessary tension among players and fans and predisposes them to conflicts. Some novel solutions based on fairness and objectivity, without sacrificing creativity, will be proposed later.

Let me get right to the point: due to the rarity of goals, even one critical mistake by the referee can change the outcome of some soccer games, compared to other sports where a referee error rarely has the potential to change the game's final outcome. A recent glaring example of such an occurrence in WC 2014 was when Bosnia-Herzegovina (BH) lost by one goal to Nigeria due to a disallowed, perfectly played on-side goal and an allowed illegal Nigerian goal (both verified by IVR which the TV audience saw but the referee had no access to), resulting in the elimination of $\mathrm{BH}$ from the tournament ${ }^{10}$ Higher scoring in most other team sports provide a built-in "reserve" which can accommodate mistakes in enforcement and still not be game-changers, whereas soccer has no such room for error. Therefore, soccer players at times feel pressured to "dive" for earning a penalty or a free kick near the box because it is so hard to score from open play. A second point is that soccer has more instances of fan violence, a destructive gang-like animosity toward the fans of the opposing team, and referee disrespect compared to all other major spectator sports. As will be explained later in more detail, based on psychosocial principles, critical mistakes in enforcement and unlimited ordinary fouls that choke open play and create a perception of unfairness and injustice are, in my view, the primary reasons why fan violence and fighting between opposing fans are more prevalent in soccer.

\section{Methodology}

As a qualitative analysis of soccer employing practical psychosocial insights and concepts, the article relies on match metrics (that is now grown to be an industry supplying voluminous and sophisticated data), evidence from empirical studies in psychology (especially social psychology), observational data based on playing and refereeing experience, interview of soccer fans and players from a variety of backgrounds, fan experience, video study of games over many years, incident analysis, and application of clinical intuition based on the author's professional background in applied psychology. Match data is cited whenever appropriate to support a claim, but was kept to a minimum so as not to distract and overwhelm the reader. The content emphasizes applications based on integration of data derived from all the sources listed above. Although some theorizing is utilized, the author has strived to support psychosocial concepts by providing references to primary sources of empirical research, publications and video evidence. Therefore the methodology may be described as a mixture of research literature review, and observational, clinical, theoretical and incident analyses.

\section{Technology Enhancing Fairness, Objectivity, and Player Conduct}

The referee does not have a 360 degree view of the players and the soccer field, which is about 10 times the size of a basketball court where there are also 3 referees in addition to IVR. Nor does he have the benefit of IVR to review a play (even from one angle), whereas the TV audience, commentators, and even the spectators (with smart phones, and TVs allowed in many stadiums) can watch the replay in slow motion and clarify what actually happened in a crucial play. If the TV audience, spectators, and TV commentators had no access to IVR (as was the case 30 years ago), this would not be so much an issue, thus literally validating the saying "ignorance is bliss." (There is, however, no suggestion 
implied here that banning IVR on stadium monitors and by TV broadcasters altogether is a solution.) It is ironic that referees are unaware of a bad call or no call until after the game, which is too late. Moreover, restitution to the wronged team after the game is over, or delayed punishment of the offender, is not the most effective form of justice except in certain administrative matters. Effective discipline and order happen when the punishment immediately follows the foul, remedial action is consistent, and sportsmanly conduct is rewarded $^{22}$. The players are now extremely adept at concealing their fouls, feigning victimization by fouls, and exaggerating injury, all for gaining an advantage by confusing the referee ${ }^{6}$ They are emboldened in taking the chance of not getting caught, knowing that the referee has no access to IVR. In many games, there are scenes in which a player falls down and hysterically writhes in agony following an apparent foul, and paramedics rush to the scene with a stretcher to carry away the player for evaluation and treatment. In the vast majority of such instances, the injured player gets up and joins in the ongoing game. One also witnesses scenes in which both involved players are rolling on the ground to win sympathy from the referee and to make him believe that it was the other player that committed the foul. It seems they are trying to outperform each other in convincing the referee to give the card against the other or to groom the referee to go easy on the player the next time. Unfortunately, these enviably talented players are tempted to resort to this level of manipulation for a slight advantage because it is difficult to win a game or assure a fair call due to the absence of objective means for verifying a crucial play. Players in other sports rarely need to employ manipulative histrionics because IVR functions as a means to ascertain objectivity and encourage honesty. The erratic enforcement and the referee's lack of objectivity may be the major reasons why players compromise their integrity of conduct in the context of a game whereas they are likely fine citizens elsewhere.

I have heard anecdotal reports that players practice clever fouling tactics. ${ }^{6}$ Even if this is hearsay, players are resourceful enough to figure out on their own how to conceal fouls and how to feign or exaggerate injury. Often a leading team kicks the ball away to kill time and the lagging team picks up the ball and hands it for a quick start, and all the while their adoring young fans are watching and learning from their idols' selfish behaviors. Social psychology research has convincingly shown that children model their idol's behavior ${ }^{20}$. Certainly, athletes are not to be held to saintly standards, but such prevalence of gamesmanship in soccer, in my considered opinion, is a symptom of helplessness and frustration among players. Besides missing foul calls, it is not uncommon that the referee books a player who was genuinely fouled, believing that the player was simply feigning as the victim of a foul. Both are injustices that undermine the fairness, integrity, and the entertainment value of soccer. The most infamous example of successful cheating would be Maradona's "hand goal" ", although one could appreciate his ability to execute such a sly move creatively and spontaneously without being caught by the referee. Doesn't the fact that it is all right to foul and fool the referee as long as you can get away with it send the wrong message to players? Of course, players are not Gandhi and, therefore, nobody expects them to voluntarily confess to a foul or refuse a penalty because no foul was committed. Even if players or coaches attempt to correct the referee in their favor or against them, the referee is likely to see it as a show of dissent. To the contrary, due to the low scoring, we should expect as a matter of practical reality that most players and coaches will do everything they can to influence the referee in order to gain an advantage and win a game. If you watch soccer on TV, you will see at least one blatant mistake (some of which are game changers) per game. Although it is the referee's solemn duty to safeguard the fairness of the competition, modern technology has clearly shown in almost every soccer game that it is humanly impossible for the referee to call the actions correctly without reliance on technology.

The players know that there is a decent chance they can get away with fouls and cheating. Therefore, the game has evolved into one with an attitude of "whoever can get away with cheating and tricking the referee the best has an advantage," even if the deception is obvious to everyone else. By denying the referee access to an objective tool that is widely and easily available and is routinely used in other sports, the referee is put in the difficult predicament of having to stand by bad calls, which is frustrating to players, coaches and fans. The referee is unfairly forced to face the indignation for his bad calls when he does the best he can humanly do without assistance from modern technology. The players both try to trick him and even curry favor with him. They try to steal a win from under his nose. The losing team and their fans are not happy with him. The winning team thinks they won because they deserved to win, and if they win because of the referee's mistake, any gratitude toward the referee is meaningless. Therefore, the referee's lack of full objectivity, as is the case now, makes him the target of frequent criticism from both the winning and the losing teams, which should make one feel sorry for him. The officiating errors could also explain the occasional violence against the referee by players and fans whose cumulative frustration resulting from bad calls can cause them to snap. Coaches also get extremely frustrated because many develop a parent-like loyalty and emotional attachment to their respective teams and players and, therefore, at times they too react out of helplessness. If referees are unable to be objective, there is the potential that they could be subjected to enormous pressure by external forces to manipulate the outcome of the game. If the referee had access to modern technological means with which he could be objective in calling the game, he could not only be more forceful and confident in his officiating but also minimize outside influences, including limiting the alleged influence of organized betting and match-fixing related to soccer that have received much publicity lately ${ }^{18}$. This could result in a calming effect on the players, fans and coaches, and lead to 
less inter-player and player-referee conflicts. TV commentators clearly see the injustice when fouls are not enforced and when players get away with cheating, but they, like the referees and coaches who are aware of the problems affecting the game, are also helpless and reluctant to voice their frustration, perhaps in deference to FIFA. So it is understandable that most of them so often minimize and rationalize the outrage by the saying, "this is soccer, what do you expect."

\section{The Reason for Frequent Fan Violence in Soccer}

Fair-minded people feel outraged in the face of injustice and unfairness which, in soccer, occur when a foul goes unpunished, the punishment for a foul is minimal, a foul is called when in fact there was no foul, the punishment is excessive, a foul is serious enough to cause injury, a fair goal is disallowed, an unfair goal is allowed, etc. IVRs allow the fans to see all the fouls and the mistakes in the referee's calls, whereas the referee is not privy to that. Therefore, it is easy to understand how the fans' strong emotional attachment to their teams and players lead to outrage in response to multiple unfair calls or even a single crucial mistake on a call that cost their team a game. This is not to suggest that most calls are wrong. In fact, most calls are right. However, the normal instinct of people is to want to correct any injustice. It is easy to see why some offended fans that do not have optimal self-control retaliate by acting out their frustration and anger. The disinhibiting effect of alcohol obviously facilitates the inappropriate venting of the justifiable anger against injustice, but even without alcohol, people feel oppressed in the face of injustice. The normal mental process of the fans' strong identification with their team and players make them feel as if they themselves were unjustly treated, abused and cheated, and the perpetrator was allowed to get away with it.

I believe that soccer hooliganism can be at least partly explained by fan frustration precipitated by mistakes and unevenness in officiating the game that at times even lead to unjust outcomes, and the flagrant and game-changing fouls, rather than explained away as misconduct and rowdy behavior. It is an established social psychological concept that frustration facilitates, and almost always forms the foundation for, aggression ${ }^{23}$. A revengeful mob mentality that supplants individual responsibility could, therefore, be easily triggered by unfair critical calls that lead to their team's loss ${ }^{21}$. Although external control systems (such as the judicial system, fences, jails, etc., which have done a decent job of containing misconduct) have decreased fan violence and hooliganism, the focus here is more on the playing dynamics and the officiating that contribute to hooliganism. If my hypothesis is correct, there will be significantly less hooliganism and fan violence if FIFA enacts rules to ensure fair and just officiating with the aid of IVR, thereby making the game more honest. It is significant that Pele, in his most recent book titled Why Soccer Matters (page 278) ${ }^{13}$, expressed his concern that the enormous power and prestige the soccer leadership attained from the popularity of soccer is not being used appropriately and responsibly for the benefit of the game, the players and the fans.

\section{Theories to Explain FIFA's Objection to IVR}

It is an established psychological concept that understanding the underlying reasons for the behavior eases the resistance to its change. Therefore, I have several theories for academic discourse that I would propose as to why FIFA has been hesitant to embrace IVR. The GLT (Goal Line Technology) is definitely a welcome step by FIFA, but when the gold standard of IVR is readily available, why should the players, fans and coaches settle for a piecemeal technology that is more like a flashlight when they can have a floodlight with IVR? FIFA is composed of representatives from many nations with different expectations and technological capabilities, making it difficult to get consensus on expediting the necessary changes in the existing rules. Another theory is that since the referees are the direct representatives of FIFA, if the referee remains the ultimate judge instead of the controversial calls being verified through objective means like IVR, FIFA gets to wield enormous power independent from the players and the game itself. By not letting the referee use modern technology for accurately enforcing the rules and letting the players and the games decide the outcome as fairly and objectively as possible, FIFA retains considerable control over the players, coaches, teams and the game. FIFA manages this process (consciously or incidentally) through its representative referees who have no access to an objective instrument to independently check and verify even crucial unsure calls and plays, and thereby essentially holding on to the power over the control of the games, and even inadvertently deciding the ultimate outcome of some games, as illustrated by the recent BH-Nigeria game. ${ }^{10}$

\section{Unlimited Ordinary Fouling Chokes Team and Individual Play}

The solo runs by some of the most distinguished players, like Pele and Maradona, were so rare because any defender can commit ordinary fouls limitlessly to kill the run and stop the game dead in exchange for a measly free kick. The few solo runs, including the most famous one by Maradona against England that miraculously survived fouling, have become classics. ${ }^{14}$ If the foul is executed well, the offender usually gets away with it. Granted that soccer is primarily an interactive and cooperative team game, it still is the individual brilliance of some superstars that truly excites and entertains the fans. For instance, when Pele played for New York Cosmos years ago, most of the games he played were sold out, whereas the other games were not. ${ }^{13}$ It was reported 
in 1967 that two factions in the Nigerian civil war agreed to a 48-hour ceasefire to watch Pele play. ${ }^{12}$ I doubt that they would have agreed to a truce to watch even two well-known teams without the excitement of Pele. Bank's amazing save of Pele's brilliant header in the $1970 \mathrm{WC}$ is still cherished. ${ }^{9} \mathrm{I}$ am citing these instances only to highlight the unique entertainment and excitement value of individual superstars well above and beyond the draw of the team as a whole, not at all to minimize the importance of team play.

Even fouls that draw yellow or red cards are so disruptive to the flow of the game that in many instances the punishment does not adequately compensate for the lost scoring chance. Unlimited ordinary fouling not only suffocates the game but also kills brilliant solo runs by gifted players, which make the game much more interesting for the fans and for the players. When Messi makes a brilliant dribble and is intentionally fouled by a defender in exchange for just a free kick, fans feel frustrated, and no one would describe the foul as a brilliant move and applaud. Soccer injuries due to fouls, resulting in players sidelined for months, are not uncommon, and it is often the gifted player that is targeted for fouling. One may recall the incessant fouling of Pele in many games, which somehow gave the impression that the opposing team's main strategy was to neutralize him as soon as the game started. There does not seem to be enough of a disincentive for a team not to foul hard a Messi, Neymar, or Ronaldo, though I do not know of any coach that would overtly employ or encourage this strategy. In summary, the overall impression is that the cumulative effect on the game of all the problems discussed above is that soccer is still a contentious sport constrained by frequent fouling, lots of activity but not much to show for it except a goal or two, frequent stops, injuries to players, errors in enforcement (which at times are game-changing), player, coach and fan frustration, and players sometimes getting away with intimidating, mobbing and showing contempt for the referee, and a lack of awareness by many of the full extent of the problems. The solutions discussed below offer food for thought in a pursuit to enhance the playability, goal scoring, and entertainment value of soccer. If my analysis turns out to be correct, paradoxically, by letting the players, the teams and the game gain more power as playability is maximized, FIFA will not only regain the industry's rightful admiration through visionary leadership and innovative thinking, it will also be fulfilling its primary organizational goal, enshrined in its Statutes, "the constant improvement of football."17

\section{Solutions for Discussion-the Less Difficult Step}

Solutions are possible only after admitting the existence of the problems. This is the first and the most difficult step on the path to the resolution of any problem, whether for individuals or for organizations. It is even harder for the insiders to appreciate the full extent of the problem due to various mental processes that psychologists are well aware of.
Moreover, a venerable and hierarchical organization like FIFA might be somewhat resistant to change from within due the weight of its own internal organizational dynamics and entrenched governance procedures. However, I have no doubt that the officials within the organization are reasonable, educated, and sincere soccer lovers who would respond to logic, study the problems and solutions described herein, and implement workable solutions for the benefit of soccer and the fans.

Obviously, it is in FIFA's interest for soccer to achieve even greater popularity among nations like the United States that now have other sports that are more captivating, partly because these other sports are constantly on the lookout for fine tuning rules and embracing technology for the fair enforcement of the rules in order to make their games more entertaining for the spectators and TV audience. NBA and American football are prime examples. For instance, interest in NBA has been steadily growing in Europe and Asia, I suspect at least to some extent at the expense of soccer. Although the U.S. soccer TV audience has been on the rise (thanks partly to the changing demographics), with spikes during major soccer events like the WC, especially when the U.S. team does well, the major U.S. networks have been reluctant to sponsor soccer games partly due to the lack of ad spots, but IVR might offer a practical solution.

When a game is played fairly, the losing team and fans will be disappointed, not outraged, about the outcome. They will understand that the outcome was just. They will realize that the team that played better deserved the win. Instead of the match causing ill feelings, opposing fans fighting, or at worst, rioting, fans of both teams are likely to celebrate and have fun. Instead of one side feeling like they stole the game and the other side feeling like they were robbed, both sides would feel they had enjoyed a good game. If the winning fans realize that their team stole the win, how can they truly enjoy the win? As promised, some novel solutions are described below for a healthy debate.

\subsection{Bring the Technology of IVR into the Soccer Field}

Soccer is overdue for the objectivity and honesty afforded by IVR. The official could confidently enforce the rules using IVR for crucial calls that he is unsure of, with an opportunity for the coach to exercise a few maximum number of challenges per game for a set fee per challenge that could mostly defray the cost of setting up IVR. If players know that IVR is in effect and they will be caught, they are very unlikely to commit serious fouls, avoiding nearly all yellow and red cards and related interruptions, injuries and wasteful stops. The stark reality is that due to frequent fouling, injuries, bookings, altercations, player histrionics and free kicks, the play already is stop-and-go. Furthermore, the stoppages are likely to be less frequent overall compared to the present due to the players fouling much less. Interestingly, IVR may not always require additional stoppages because the games would already be interrupted in most instances of IVR. Used wisely, say for TV ads, these time windows would also generate considerable additional 
revenue for the teams and FIFA, while more importantly ensuring a fair enforcement of the game. Affordability of the technology for the developing nations is a concern but perhaps developed nations could assist the needy developing nations with setting up IVR systems, allocating to them some of the revenues derived from IVR challenge fees, TV ads, rising TV ratings, etc., further extending the already existing international cooperation and assistance programs. While IVR certainly is not a panacea, it should substantially improve fairness in officiating and minimize conflicts. The referee's judgment is still necessary in interpreting the IVR, attesting to the important reality that even with the best of technology, human judgment and sensibility will and should always have a central place in refereeing decisions.

\subsection{Devise Constructive Alternatives to Expulsion (Red Card)}

Expelling a player from a game is not sufficient to deter players from committing serious violations, as evident from the fact that an average of 4 yellow cards and one red card is issued game after game. ${ }^{5}$ Expelling just one player might not make much of a difference because there are still 10 extremely fit players that can fairly well compensate for the loss of one. If the expelled player is a regular player and if the foul results in the disabling of a gifted player of the likes of a Pele, Messi, or Neymar, it is like trading a pawn for a queen, which still strategically favors the decision to foul hard enough to disable or slow down a star player and take the chance of getting expelled. Furthermore, expelling a player hurts the team more if it happens early in the game, but less so towards the end of the game. If the expelled player is a high value player, it also helps the opposing team in the next game because the expelled player is required to sit out the very next game. Thus, the punishment does not compensate the victimized team sufficiently, while benefiting another team that was not victimized. Actually, the overwhelming incentive is for a team leading by one goal to foul hard to foil an imminent goal towards the end of the game, even risking serious injury to the forward, thereby protecting the lead, if the only risk is losing the fouling defender till the final whistle. The fact that the expelled player can be replaced by another player for the team's next game gives the illusion that the team is penalized substantially, but in reality, the fouling team still is allowed to field 11 players for the next game.

Another drawback to expelling a player is that it deprives all the fans and spectators of the opportunity to watch and enjoy his play. For instance, imagine a hypothetical scenario where a superstar gets frustrated by relentless fouling and taunting that are ignored by the referee or done surreptitiously, and he reacts out of sheer desperation, which the referee happens to see, resulting in a red card. Who are the real victims? Obviously, the ones really punished (if players of the caliber of a Pele, Maradona, Ronaldo or Messi are expelled) are the spectators, the TV audience, the team, and the TV broadcaster that bought the rights expecting the superstar to play the full game. Instead of enhancing the quality and the entertainment value of the game, the expulsion usually has the effect of causing a demoralizing negativity and ill will among the fans and the team that lost such a player, and among the entire audience as well, especially if it is a star player that fans have been eagerly waiting to see. To further expand on this important point, if a gifted player is expelled, it is as if the opposing team received a reward and the team that lost the gifted player was over penalized, causing a disappointment to all the spectators. This dynamic could even tempt teams to devise tactics to intentionally provoke a superiorly gifted player like Messi or Ronaldo into a frustrated reaction that could win a yellow or a red card as a strategy to neutralize him and gain an advantage for the opposing team. Such a potential scenario can be prevented by a coach monitoring the play and exercising an IVR challenge if the referee fails to notice players provoking each other. Surely, there must be another civilized way to penalize the gifted players and the teammates without having to expel them and thereby depriving paying fans of their right to see them play the full game.

It is a fact that penalty shoot outs are exciting to watch because the fans can see their stars scoring goals. Therefore, from a human and rational standpoint, a more effective, entertaining, constructive and play-enhancing deterrent to serious fouling is to award a penalty for all red card offenses without the necessity of expelling a player, with the referee having the final and unquestionable authority to also expel the player if the foul deserves both a penalty and expulsion, which some egregious incidents involving injury or an attack on the referee will call for. Due to the rarity of open goals in soccer, it is likely that players and teams will then devise strategies to feign and exaggerate injuries in order to trick the referee into a penalty. However, I have no doubt IVR will practically eliminate this possibility because players will then be rewarded more for showcasing their skills and talents rather than resorting to fouls and histrionics.

\subsection{Limit the Number of Fouls to Unleash the True Beauty of Soccer}

Depending on the league, the average number of regular fouls is about 30 per game ${ }^{5}$. Currently there is no limit to the regular fouls that kill the momentum and continuity of the game, which sometimes makes soccer frustrating to watch. Although referees have the discretion to book a player for a "pattern" of excessive fouling, in the vast majority of instances a free kick is all that is given. Besides, referees do not keep track of ordinary fouls, unlike yellow and red card fouls, so it is difficult for them to judge a player based on his fouling history. Therefore, a numerical limit on regular fouls is desirable to maintain the flow and the elegance of the game, as is successfully employed in various other professional team sports. An idea for discussion is to set a limit of more or less 8 regular fouls per team with a yellow card foul counting for 3 regular fouls, and a red card foul counting for 5 regular fouls. A penalty is then given for the ninth foul and for every five fouls exceeding the maximum 
allowed. The so-called "professional" fouls might deserve a yellow card. Some such rule to limit fouling will have the potential for making soccer one of the most exciting games to watch, with the goal average rising to an exciting and entertaining 5 to 6 instead of the current 1 to 2 . An average of about 5 open goals per game is certain to keep the interest of the spectators and the TV audience throughout the game, and is desirable for differentiation and entertainment to be optimized without diluting the value of the goals. To be fair, there are goal-less games that are still entertaining to watch because they are played cleanly with great passing, dynamic ball movement and little fouling, but unfortunately, they are few and far between. The beauty of soccer is that even a save is appreciated, as shown by the great Pele when he would occasionally approach the goalie to congratulate him for a great save as a gesture of genuine sportsmanship that is worthy of emulation by players at all levels, but I have never seen a cherished foul, and nor should there be one.

Another advantage to expanding the outcome range from 1-2 goals to 5-6 goals per game is it enhances the power of differentiation between teams without making the outcome highly predictable. The paucity of goals (the sole outcome criterion in soccer) along with erratic and subjective enforcement, and the ease with which gifted players can be neutralized or disabled, significantly contribute to make the outcome of a soccer game a near 50-50 event. ${ }^{5}$ Therefore, it is foreseeable that such a lack of differentiation between teams promotes proliferation of betting, and tempts organized antisocial groups to exploit soccer, with its negative social and criminal repercussions. By solving some of the problems described here, the game will become slightly more predictable, giving it more integrity, objectivity, and reliability while discouraging excessive activity by criminal elements to attempt to influence the outcome of the game.

\subsection{Minimize Aerial Collision Injuries}

Heading is an essential soccer skill that yields beautiful goals and passes as recently illustrated by one of the most memorable headers by van Persie in WC $2014^{19}$. However, aerial collisions are inherently more prone to cause injury. A source of major injuries is when players jump for contested headers, especially if one player jumps from a stationary position and another player sweeps in airborne like a missile, knocking down the player who was the most proximal to the ball. Depending on the mass and the velocity of the torpedoing player, a simple law of physics dictates that injury to the relatively stationary player would be highly likely. A split second deployment of the elbow or knee could cause serious injury, and is difficult for the referee to visualize and call in real time, especially when the line of vision is obstructed by either of the players or if the move is made under the pretext of a fair challenge. Unscrupulous players take advantage of the inherent ambiguity of the header to inflict injury to opponents while making it look like a fair tackle. A blow disguised as a natural move happening in a split second can only be properly judged in slow motion in replay. Although physical contact rules relating to interference already exist, they are rarely enforced due to the extreme difficulty of verifying the midair actions that take place in milliseconds. TV replays reveal many instances of a player using the other player for leverage to reach the ball. Therefore, an enforcement strategy is proposed without significantly affecting the dynamics of the game. If a player has already established "possession" by virtue of being closest to the point of optimal contact with the ball, that player should be deemed having the right of way, so to speak. A physical interference by a player who has no right of way and who has little chance for a fair play should be an automatic yellow card foul. If such a concept is adopted by the players and the referee, there will be less likelihood of a heading player that is in the perfect position to head the ball being bulldozed by another player who has no chance for a play on the ball, but instead only ends up hurting the other player and ruining the beauty of the game in the process. This concept of "possession" or "right of way" will also enable the referee to be much more vigilant when judging the actions of the airborne player and deeming it a violation if physical interference or excessive physical contact with potential for injury occurs, even if the challenging player wins the ball. Another option to consider is to have a challenging player touch the ground within 3 to 4 feet of the player with the "possession" before contesting for the header. Some such restraint should cut down the facial, forehead, and head injuries related to contested headers. Ultimately, IVR, if implemented, will resolve the ambiguity for the referee, and keep the players honest and safe.

\subsection{Improve the Advantage Rule}

Though the advantage rule facilitates the flow of the game and should be encouraged when possible, the effective advantage is compromised in many instances in reality if the fouling player is given a free pass or let go with just a warning. For example, when a player is tripped or pulled or fouled by whatever means and the player recovers and is given the go ahead as an advantage play, that player still loses precious milliseconds, which matter a lot in soccer, for example, for a chance to beat the off-side or dish a pass out for a precisely timed run, as any experienced player or coach would agree. Therefore, it is important to book the fouling player for the foul after the play is stopped for another reason and make the fouling player accountable, even when the foul is not totally disruptive. Otherwise, the players develop the attitude that it is better to foul and take their chances; at worst, if the foul is successful, a free kick is all that the victimized team gets. If the foul fails and results in an advantage play, it still is not bad, and probably it will have accomplished the purpose, because the fouled player's speed and moves are very likely interfered by the foul. In fact, fouls that result in an advantage play while slowing it down may be the most sophisticated and the most professional of all fouls that could be pulled off consistently only by the finest of defenders. If the advantage play is given and if the perceived advantage does not materialize, the referee should not hesitate to use appropriate remedies including stopping the play and 
awarding appropriate punishment, or book the offender later, but referees rarely do this in practice, contributing to the unruly conduct of players, and fan frustration. Therefore, even a harmless foul should be accounted for, just as a shooter is still charged with a crime even if no one gets hurt. If not, the unlimited fouling culture in soccer will perpetuate almost a no risk attitude towards fouling, which is detrimental to facilitating the beauty and elegance of the game.

\subsection{Protect the Gifted Players}

By protecting the gifted players, soccer is protecting itself. The reason why high value targets and VIPs are afforded more security is because they are at increased risk and therefore need more protection than ordinary people. Nobody complains about the need for such protection, and sensible people do not think that VIPs are preferentially treated or that ordinary people are discriminated against when some VIPs legitimately need the extra protection. Obviously, protection is needed where one is most likely to be at risk which, for a gifted player, is in the soccer field. Therefore, there must be a mechanism to protect FIFA's and the team's most valuable players (truly, assets) from frequent fouling by players in order to maintain the entertainment value of the game. Besides, fans fill up the stadium, drawn by the presence of even one gifted player. All soccer fans, coaches and players would agree that what happened to our superstars from Pele to Neymar should not be allowed to happen to any other player in the future in any civilized society. ${ }^{3,4,15}$ I am proposing an idea for the specific purpose of protecting our superstars from flagrant fouling and injuries. Let me illustrate the application of the protection plan using Messi, who is a contemporary superstar. Clearly, Messi does not need protection in his home or on the street where he is not a target of fouls. However, as a high value target on the soccer field, he needs to be protected from excessive and reckless fouling and getting injured, thereby rendered unable to play. One way to protect superstar players on the field is by having the coach or captain of each team at a certain level of competition designate a high value player before the game. Any fouling of this one player on either team should be penalized by double the points levied against fouling a teammate. For example, a basic foul on Messi will cost 2 points compared to 1 point for fouling a regular player; a yellow card foul on Messi will cost the fouling team 6 points instead of 3 points; and a red card foul on Messi will cost the opposing team 2 penalties instead of one penalty. If this rule had been in effect for the 2014 WC, then perhaps Neymar would have been spared the assault on his back which nearly ended his career and almost made him a paraplegic, and without the loss of their star player Brazil may have fared better. It is my firm belief that implementation of some of the ideas described here will make soccer much more beautiful, entertaining, peaceful and safe for fans, players and referees.

\section{Conclusion}

A ball and some ground to run around are all that is needed to play soccer while having a lot of fun, socialization, and a healthy dose of aerobic exercise. This simplicity is perhaps what gives it such a universal appeal. Soccer is larger than any organization, and truly belongs to the fans and to the players. However, for soccer to achieve its full potential, we need to create a playing environment in which the players can showcase their skills without the threat of being seriously fouled, injured or sidelined, without having to resort to desperate measures, and without having to employ gamesmanship and dishonesty. And when the destructive and negative forces in the human psyche are kept latent by the formulation and enforcement of rules that keep intentional fouling, injuries, silly stoppages, histrionics and cheating to a minimum, and maximize opportunities for open play goals through team play and solo runs, the game not only becomes safe but also much more creative and entertaining. The author believes that soccer could do much better as a sport, both for its entertainment value and as a unifying force in society, as shown by the halting of an African civil war for watching Pele's game. If the problems described here are taken seriously, debated, and reasonable solutions are implemented, soccer has tremendous potential for becoming even more entertaining, elegant and beautiful, and for bridging some connections among fighting nations, almost all of which have a large following of people who play and enjoy soccer. Allow soccer to fulfill its true potential.

\section{References}

[1] SirPeleForever. (2008, Oct 11). Pele Greatest Ball Trick [Video File]. Retrieved from http://youtu.be/ryIGWJx_CmA

[2] Football!: (2011, June 29). Pele Vs Czechoslovakia 1970 by Zouzinho [Video File]. Retrieved from http://youtu.be/wmOY15DSUaM

[3] Radnedge, K. (2000). The Complete Encyclopedia of Soccerthe bible of world soccer. London: Carlton Books.

[4] Henshaw, R. (1979). The Encyclopedia of World Soccer. Washington, D.C.: New Republic Books.

[5] Anderson, C. and Sally, D. (2013). The Numbers Game. New York, NY: Penguin Books.

[6] Berikson Sports. (2011, April 22). Worst Football Divers and Cheaters [Video File]. Retrieved from http://youtu.be/LCH2wXK4T4

[7] Harris, K. (2003). Pele: His Life and Times. England: Welcome Rain Publishers.

[8] Over Vines. (2014, July 5). Neymar Injury Ends His Career World Cup: Video explains why and how it happened [Video File]. Retrieved from http://youtu.be/BPDsIIn5sTU

[9] Swan, J. (2009, June 26). Gordon Banks - The Greatest Ever Save [Video File]: retrieved from http://youtu.be/ngE9RCAdWaE 
[10] Singer, M. (2014, June 14). 2014 FIFA World Cup: Nigeria Wins 1-0, Knocks Out Bosnia [Video File]: http://www.cbssports.com/world-cup/eye-on-worldcup/24593074/fifa-world-cup-bosnia-herzegovina-vs-nigeriapreview

[11] Renee, M. (2010). Fouls on Pele [Video File] Retrieved from http://youtu.be/yIWjPGG8fDY

[12] Pele. (2006). The Autobiography. England: Simon \& Schuster.

[13] Pele, and Winter, M. (2014). Why Soccer Matters. New York, NY: A Celebra Book.

[14] Ify212. (2009, March 5). Maradona Vs England (1986 World Cup) Both Goals [Video File]: http://youtu.be/KY40_rBvSk

[15] Thereflink. (2007, Nov. 23). Ramos Elbow [Video File]: http://youtu.be/30rSHY9aFBI

[16] Joseph, S. (2014). Notes based on personal observation of friendly match: Brazil Vs Columbia. Played at Sun Life Stadium, Miami, FL on Sept. 5, 2014.

[17] Fifa.com (Official website, 2014). Mission Statement. http://www.fifa.com/aboutfifa/organisation/index.html

\section{Biography}

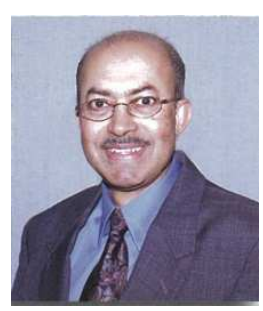

(Psychiatrist, Clinical psychologist, soccer player, and referee. MD: U. Juarez, Mexico; MPH: Public Health, Harvard \& MIT; PhD: Clinical psychology, U. Ottawa. MA: Psychology, U. Kerala; BA: Psychology, Union Christian College, India. Author: Symptom-Focused Psychiatric Drug Therapy, and Personality Disorders) Thanks to Rev. Dr. Augustine Mendonça, Dr. Deborah Schwartz, Michelle Stanton, Dr. Cynthia Fridlich, Dr. Dinah Warner, Lisa Joseph, Annie Joseph, Dr. Maurizio Fava, Dr. Alan Fyall, Sebastian Valley, Joe Castronovo, Carolyn Wehr, John Herceg, and Dr. Jerry Wehr, for their constructive suggestions. Correspondence: 9430 Turkey Lake Rd, Suite 204, Orlando, FL 32819, USA.
[18] Forrest, B. (2014). The Big Fix. New York: William Morrow.

[19] FIFATV. (2014, Nov. 12). Robin van Persie Goal: Finalist FIFA Puskas Award 2014 [Video File]: https://youtu.be/DeKSmd-hjwo.

[20] Ross, S. (1961). Transmission of aggression through imitation of aggressive models. Journal of Abnormal and Social Psychology, 63, 575-582.

[21] Diener, E., Fraser, S.C., Beaman, A.I., Kelem, R.T. (1976). Effects of deindividuation variables on stealing among Halloween trick-or-treaters. Journal of Personality and Social Psychology, 33(2), 178-183.

[22] Ciccarelli, S.K., White, J.N. (2009). Psychology. NJ: Prentice Hall

[23] Dollard, J., Miller, N., Mowrer, O., Sears, R. (1939). Frustration and Aggression. New Haven: Yale University Press. 